\title{
The use of NDVI and its derivatives for monitoring Lake Victoria's water level and drought conditions.
}

\begin{abstract}
Normalized Difference Vegetation Index (NDVI), which is a measure of vegetation vigour, and lake water levels respond variably to precipitation and its deficiency. For a given lake catchment, NDVI may have the ability to depict localized natural variability in water levels in response to weather patterns. This information may be used to decipher natural from unnatural variations of a given lake's surface. This study evaluates the potential of using NDVI and its associated derivatives (VCI (vegetation condition index), SVI (standardised vegetation index), AINDVI (annually integrated NDVI), green vegetation function $\left(F_{g}\right)$, and NDVIA (NDVI anomaly)) to depict Lake Victoria's water levels. Thirty years of monthly mean water levels and a portion of the Global Inventory Modelling and Mapping Studies (GIMMS) AVHRR (Advanced Very High Resolution Radiometer) NDVI datasets were used. Their aggregate data structures and temporal co-variabilities were analysed using GIS/spatial analysis tools. Locally, NDVI was found to be more sensitive to drought (i.e., responded more strongly to reduced precipitation) than to water levels. It showed a good ability to depict water levels one-month in advance, especially in moderate to low precipitation years. SVI and SWL (standardized water levels) used in association with AINDVI and AMWLA (annual mean water levels anomaly) readily identified high precip-
\end{abstract}


itation years, which are also when NDVI has a low ability to depict water levels. NDVI also appears to be able to highlight unnatural variations in water levels. We propose an iterative approach for the better use of NDVI, which may be useful in developing an early warning mechanisms for the management of lake Victoria and other Lakes with similar characteristics. Keywords: NDVI, Lake Victoria, water levels, drought, catchment basin, Lake variability.

\section{Introduction}

Lake Victoria, the world's second largest fresh water lake, is refilled largely (80\%) by direct rainfall (e.g., Awange and Ong'ang'a 2006). Its annual weather patterns and water use are major factors that significantly affect its water level (Kull 2006). The extent to which these affect the water level is still debatable. Kull (2006) suggests that $55 \%$ of the fall in water level occurs because of excessive release through the Owen Falls and Kiira hydro power dams as opposed to $45 \%$ due to drought. In 2003-2006, however, the lake receded at an alarming rate (Kull 2006, Awange et al. 2008) bringing to focus the need for the constant monitoring of its water levels.

Lake Victoria is a shared resource with immense importance in sustaining livelihoods (i.e., agricultural, fisheries, hydropower generation, and freshwater, see e.g., Awange and Ong'ang'a 2006), not only within its locality (East Africa), but also as far as the Nile River stretches (see, e.g., Yates 1998). In light of its immense importance, a multi-faceted approach for monitoring its surface dynamics is necessary to provide information that would assist water resources managers and policy makers in making decisions that would 
enhance the sustainable use of the lake's waters.

Existing water-level monitoring technologies, such as tide gauges and radar altimetry, are limited to the empirical evaluation of water-surface changes. Tide gauges, for example, are limited in their spatial coverage and their in-situ use requires solving the problem of accessibility to both the observation sites as well as the data, which are often only available to government authorities (Charon and Brad 2004). To overcome these setbacks, satellite altimetry methods (see e.g., Birkett 1995; Becker et al. 2010), which are semi-realtime and less precise than the gauges, are being adopted (e.g., Charon and Reynolds 2005). The tide gauges, however, do not provide any other relevant proxy data, such as that provided by satellite imagery. Imagery can, for example, provide a time series of various measures of vegetation vigour, such as the main interest of this work, the Normalized Difference Vegetation Index (NDVI; Tucker 1979) for the extended evaluation of a lake's surface dynamics in relation to its catchment's response to weather and climate patterns.

In an environment where there is an increasing uncertainty in the prospect for adequate rainfall, the use of NDVI should be viewed as an attempt to provide input to developing enhanced water management systems that incorporate other observables such as drought indices, to adequately forecast the dynamics of a lake's surface. Drought, a condition of precipitation deficiency, has a direct negative impact on all useable water sources (McKee et al. 1993). NDVI variables should quantify and/or decipher a lake's surface dynamics as affected by local weather/drought patterns from anthropogenic water use, while also accounting for weather patterns in a given lake's catchment (see 
e.g., Mendicino and Versace 2007; Subash and Mohan 2011).

NDVI has traditionally been used for vegetation cover modelling (see, e.g., Privette et al., 1995) and was extended, for example, to epidemiological studies where, in the work of Hay et al., (1998), it was used to predict malaria seasons in Kenya. NDVI has also been shown to provide a good overview of the prevailing plant water stress as a function of the prevailing weather conditions (Hatfield, et al. 2004; Gontia and Tiwari 2010). This relationship is already being exploited by the Famine Early Warning Systems Network (FEWS NET 2011) to monitor crops and range lands in semi arid sub-Saharan Africa. It is also a known covariate with other environmental variables, such as surface cover and rainfall, especially in semi arid regions (Nicholson 2001a). In a recent study, Chen et. al., (2011) showed the potential use of NDVI to identify critical soil-loss prone areas in Xiangxi watershed, the river basin nearest to the Three Gorges Dam.

In tropical Africa, natural vegetation is generally very sensitive to precipitation. Camberlin et al. (2007) established that, even with varying mean annual rainfall amounts, for a third of tropical Africa, inter-annual NDVI correlates with corresponding inter-annual rainfall. A correlation of $r>0.5$ has been observed in semi-arid regions, with generally lower correlations in areas with mean annual rainfall above $600 \mathrm{~mm}$. However, such correlations are region dependent. Significant correlations have been observed even in areas with more than $600 \mathrm{~mm}$ mean annual rainfall (Camberlin et al. 2007), e.g., the Lake Victoria basin. Thus, depending on the location and the spatial extent of the study area, varying correlation patterns should be expected due to differing precipitation patterns. 
Nicholson et al (1990) used the Global Inventory Modelling and Mapping Studies (GIMMS) NDVI dataset (1982-1985) to compare vegetation response to rainfall in East Africa and the Sahel regions and found that in these regions, annually integrated NDVI (AINDVI) closely varied spatially with mean annual rainfall, especially at two-months time lag. The time lag is important because vegetation does not directly respond to rainfall, but rather to soil moisture, which is a multi-month integral of rainfall (Nicholson et al. 1990). However, NDVI saturates at rainfall thresholds of above $1000 \mathrm{~mm}$ due to water logging and below $200 \mathrm{~mm}$ where it readily depicts bare soil. Furthermore, Anyamba et al. (2002) suggest the possibility of seasonally predicting NDVI using observed rainfall for Africa. This would require the use of numerous active ground-based weather stations (Verdin et al., 2005). A recent use of NDVI is exemplified in the work of Kiage and Walker (2009) who apply NDVI derived from MODIS imagery to investigate duckweed blooms and other floating vegetation in Lake Maracaibo, Venezuela. Propastin (2008) applied NDVI to model the link between wetland and biomass conditions in the Ili River delta and changes in the Backhash Lake water levels, Kazakhstan, and showed that NDVI displayed significant intra- and inter-annual variability strongly correlated with the Ili River discharge and Backhash Lake's water levels.

In this study, the application of NDVI and its derivatives, namely SVI (standardised vegetation index), AINDVI (annually integrated NDVI), green vegetation function $\left(F_{g}\right)$, and NDVIA (NDVI anomaly) as proxy datasets for Lake Victoria's natural water level variations and therefore their use for monitoring lake water surface levels is assessed. The assessment is based 
on the assumption that for Lake Victoria, of all possible natural factors, weather patterns are the major natural factor governing its natural water level trends (Kull 2006; Awange et al. 2007; Swenson and Wahr 2009). This is compounded by water releases for hydroelectric power generation, which have been proposed as having largely contributed to falling water levels (Kull 2006; Awange et al, 2008). Thus, the possibility of using NDVI to discern such anthropogenic fall in water level from that due to drought is also assessed.

Broadly speaking, this study aims at identifying and evaluating the possibilities of using catchment NDVI as a proxy variable for depicting, as well as monitoring, lake surface water levels. It seeks to understand the general relationship between the Lake Victoria catchment NDVI and its water levels and therefore the applicability of its aggregated NDVI in depicting natural water level patterns. It is assumed that any functional contributions of the catchment to the water balance in terms of surface runoff, drainage, land use or otherwise can only be aggregate. Therefore, for each of the NDVI images, the focus is on the mean NDVI. To identify and understand such possibilities and associated patterns, spatial-temporal and quantitative variabilities of Lake Victoria's catchment (Advanced Very High Resolution Radiometer (AVHRR) NDVI 1987-2003) and the observed water levels were used.

\section{Study Area and Data sources}

\subsection{Study Area}

According to the United States Department of Agriculture (USDA/FAS 2007), Lake Victoria's water level is known to be extremely sensitive to mod- 
erate changes in rainfall over the lake and its large catchment. This is heightened by the fact that it is typically shallow. Thus, its recharge capacity is very dependent upon its large surface area of approximately $69,000 \mathrm{~km}^{2}$ and the tributary flows from its catchment, which extends to an area of over $184,000 \mathrm{~km}^{2}$ (Fig. 1).

\section{FIGURE 1}

Land use in the catchment is largely agricultural (Fig. 2). It is therefore prone to low vegetation cover, especially in the dry seasons, while also having a mixture of dense forest covers. Diverse land cover types exist, ranging from bare ground, rain-fed and irrigated crops, to urban areas (Fig. 2). On the Ugandan side of the catchment, the most dominant vegetation cover is rainfed shrub crops followed by generally open shrub land. In Kenya, the land cover is mostly rain-fed herbaceous crops, similar to Tanzania, except that in the latter, the crops are often punctuated by variable mixtures of savannah shrubs. A detailed description of the lake basin can be found, e.g., in Awange and Ong'ang'a (2006).

\section{FIGURE 2}

\subsection{Data sources}

The data used includes daily rainfall observations from the Entebbe meteorological station (1990-2005). This station is chosen as being representative

of the other stations within the basin due to the fact that they are within the same climatic zone (e.g., Awange et al., 2007). The primary datasets are the 
GIMMS AVHRR NDVI (1987-2003), and thirty years of monthly mean water levels (1976-2005) from the Jinja tide gauge station in Uganda. The NDVI used is a spatial and temporal subset of an improved continuous AVHRR calibrated global dataset processed under the GIMMS project. The AVHRR NDVI data processing and quality is comprehensively discussed by Pinzon et al, (2004). It has been critiqued by some authors, e.g., Tucker et al. (2005) cites Chilar et al. (1998) and Gutman (1999) who question the non-surface uncertainty in AVHRR NDVI data. However, Tucker et al. (2005) argue that their findings are mainly a result of inappropriate use of the data.

The water levels are observations relative to an established height datum of $1122.86 \mathrm{~m}$ above mean sea level, while the lake's maximum mean level is $1134.5 \mathrm{~m}$. Observations of water level fluctuations provided by altimetry missions are of major importance in monitoring water reservoirs, as they provide independent information in addition to the traditional in-situ datasets (Birkett 1995; Cretaux and Birkett 2006). Satellite altimetry water levels from Topex/Poseidon (T/P) and its follow-on, Jason-1, were incorporated for the period 1993 to 2009. T/P was the first successful repeat-orbit altimetry mission and operated in several phases in its original orbit until September 2002. The spacecraft was in an orbit with an altitude of about $1300 \mathrm{~km}$ and provided repeat measurements over a given geographical position at approximately 10-day intervals. Technical details of the spacecraft can be found in Fu et al., (1994) and the references therein. During the ten years of its operation, T/P provided 369 cycles of precise and accurate observations of water-level variations with a near global coverage. According to the pre-launched report of Benada (1997), the sea-level measurements of 
Table 1: Data source used in this study.

\begin{tabular}{|c|c|c|}
\hline Data & Source & Period \\
\hline Daily rainfall & Entebbe Meteorological Station, Uganda & $1990-2005$ \\
AVHRR NDVI & GIMMS, University of Maryland & $1987-2003$ \\
Monthly mean water levels & Jinja tide gauge (Uganda) and & $1976-2005$ \\
Satellite altimetry & NASA Physical Oceanography DAAC (PODAAC) & $1993-2002$ \\
\hline
\end{tabular}

$\mathrm{T} / \mathrm{P}$ had a precision of $2.4 \mathrm{~cm}$ and an accuracy of $14 \mathrm{~cm}$ for typical oceanic conditions, with small geographically correlated errors. Since its launch in December 7th 2001, Jason-1 has provided sea and lake surface height observations with the same global coverage and orbital repeatability of 10-days (Picot et al., 2003).

In order to obtain the lake level heights (LLH) of Lake Victoria during the ten years of T/P's satellite operation (1993 to 2002), we used data (Merged Geophysical Data Record (MGDR)) provided by the NASA Physical Oceanography DAAC (PODAAC) at the Jet Propulsion Laboratory, California Institute of Technology. To cover the remaining period of the study, we examined the Jason-1 Interim Geophysical Data Record (IGDR) datasets that are available via the PODAAC website. These satellite altimetry data provided independent datasets fulfilling the same task as the Jinja tide gauge, while offering the possibility of comparison (and controlling outliers) with the tide gauge dataset (see Fig. 3). Table 1 summarizes the data source used in the study.

FIGURE 3 


\section{Methodology}

\subsection{Using NDVI}

NDVI is the ratio of the reflectance difference between the near-infrared (NIR) and visible $(\mathrm{R}=\mathrm{red})$ bands and the sum of the reflectance of these two bands (e.g., Tucker, 1980). It is expressed as

$$
N D V I=(N I R-R) /(N I R+R)
$$

It is primarily a biophysical measure of vegetation vigour that directly assesses the level of photosynthesis rather than the extend of canopies (Hatfield et al. 2004), and is a spatially continuous variable. It can be derived from imagery provided by any satellite sensor that scans in the visible (red) and near infra-red bands, and is expressed as a normalized ratio ranging from -1 to +1 . NDVI was primarily developed to improve the sensitivity of the simple ratio $S R=N I R / R$ to vegetation structure and cover. The NDVI is sensitive to soil reflectance in sparse vegetation, however, it saturates faster in dense vegetation. In dense cover, the NIR signal increases while the red signal stagnates (Liang, 2004). On the other hand, the SR saturates slowly and has a good ability to differentiate soil from vegetation (Baret and Guyot 1991).

The impact of drought is directly observable in the five major useable water sources; soil moisture, groundwater, snow pack, stream flow, and reservoir storage (McKee et al., 1993). NDVI depicts vegetation vigour, which is an ancillary reflection of precipitation variability, especially in semi arid regions. It therefore depicts plant water stress, which is a direct function of drought. This dynamic characteristic of NDVI makes it very useful as a 
drought metric, specifically for agricultural drought monitoring, for example by identifying when the available amount of water falls below that required by plants (McVicar and Jupp 1998).

In practice, NDVI as a drought measure is normally used in its linear transforms, e.g., the green vegetation fraction $F g$, as suggested by Gutman and Ignatov (1998), which is the normalized NDVI given as (Carlson and Ripley 1997)

$$
F_{g}=\left(N D V I_{i}-N D V I_{\min }\right) /\left(N D V I_{\max }-N D V I_{\min }\right),
$$

where $N D V I_{i}$ is the NDVI for the individual pixel $i$ from Eqn. (1), $N D V I_{\text {min }}$ is the NDVI of bare soil and $N D V I_{\max }$ is the NDVI of full vegetation cover. $N D V I_{\min }$ and $N D V I_{\max }$ are constant global values. This value is used to monitor the spatial dynamics of greenness, especially in dense vegetation cover (Liang, 2004). Gutman and Ignatov (1998) suggested values of 0.04 and 0.52, while Carlson and Ripley (1997) suggested 0.2 and 0.7 as the typical minimum and maximum values, respectively. Furthermore, the $F_{g}$ has been extended to model the fractional cover through $F_{c}=F_{g}^{2}$, that is the proportion of the ground area covered by the projection of plant leaves and stems (Hatfield et al., 2004).

The use of $F_{g}$ is synonymous with the vegetation condition index (VCI) of Kogan (1997), given by

$$
V C I_{i j k}=\left(N D V I_{i j k}-N D V I_{i, \min }\right) /\left(N D V I_{i, \max }-N D V I_{i, \min }\right),
$$

except that the VCI uses local minimum and maximum NDVI values. The VCI specifically assesses the temporal variability of the NDVI signal while minimizing the first-order effects of spatially variable environmental factors 
like climate, soil and, vegetation types and topography (Kogan, 1997). In Eqn. (3) the $N D V I_{i, \min }$ and $N D V I_{i, \max }$ are the multi-year minimum and maximum NDVI values, respectively, for NDVI image pixel $i$, while $j$ and $k$ represent a given month and year, respectively. NDVI is also commonly used as the standardized vegetation index (SVI), first proposed by Liu and Negron-Juarez (2001), i.e.,

$$
S V I_{i j k}=\left(N D V I_{i j k}-N D V I_{i j, m i n}\right) / \sigma N D V I_{i j}
$$

where $\sigma N D V I_{i j}$ is the standard deviation of NDVI for pixel $i$ in month $j$ This is statistically a $Z$ - score of observed NDVI based on multi-year mean NDVI values and their standard deviations on a chosen accumulation time scale. Bayarjargal et al. (2006) suggest that this time scale can be weekly, biweekly, monthly or seasonal as appropriate, depending upon the required precision and data availability. This is synonymous with the standard precipitation index of McKee et al. (1993). Also in use is the NDVI anomaly (NDVIA), the departure of NDVI from its long-term (multi-year) mean for a chosen accumulation period, expressed as (Anyamba et al., 2001)

$$
N D V I A_{i j k}=N D V I_{i j, m e a n}-N D V I_{i j k}
$$

where $N D V I_{i j k}$ is the monthly NDVI for pixel $i$ in month $j$ for year $k$, $N D V I_{i j, m e a n}$ is the multi-year average NDVI for pixel $i$ in month $j$.

\subsection{Data Processing}

The GIMMS NDVI images have the pixel values (NDVI values) factored by 10000 to enhance visualization without loss of information, therefore the 
values range between -10000(-1) to 10000 (1). For the Lake Victoria catchment, pixels with NDVI values of less than zero were identified to be wetlands, marsh lands, beaches, or muddy waters. Such land cover is quite common within the lake catchment area, since transition zones between the lake and dry land exist. These bad/low pixels were all masked out, including open water (-10000), as well as missing values (-2006). This was necessary because any water to water-logged land cover will tend to have saturated constant NDVI values whose pixel values will distort the mean. The analyses were restricted to the Lake Victoria catchment basin using a Catchments Area Mask (CAM), which was digitized from the general outline of the catchment (Fig. 1) and projected onto the NDVI image coordinate systems (Albers Conical Equal Area). Its area outside the lake, but within the catchment, was rasterized at a matching $8 \mathrm{~km}$ resolution. GIS map algebra tools were used (Fig. 4) for masking out the bad pixels from each of the NDVI bimonthly images (X). Furthermore, using GIS overlay tools, the resulting Images (Y) were further area masked by the CAM to obtain the required NDVI images $\mathrm{CAM}(\mathrm{Y})$. Since the catchment lies within the equatorial belt and is therefore sufficiently vegetated, the masking inherently also removes insufficiently vegetated pixels, thereby improving the accuracy of NDVI modelling (see e.g., Kastens et al., 2005).

\section{FIGURE 4}

Within a given month of any year, there were bimonthly images with approximately the same NDVI statistics, and one could choose either image. However, in this study, a monthly mean NDVI value was computed from the 
two images to formulate the primary NDVI values used (Fig. 4). This was done for all studied months. Entire catchment mean NDVI values rather than the individual pixel values were considered. Even then, within each of the images, the distributions of NDVI values are approximately normal, thus suggesting heterogeneous vegetation cover in the catchment, despite the low spatial resolution (i.e., monthly).

\subsection{Analysis Methods}

The global and internal structures of the datasets were explored and found to be useful for designing the NDVI data derivation algorithms, and in developing assumptions used in the data analysis. Various NDVI/water level co-variability trends were assessed. NDVI as a predictor variable was analysed both in its raw form (Eqn. 1) and its transformed forms (drought metrics, Eqns. 3-5). Correlation analyses were then performed to identify the extent of the association between the water levels and NDVI. Correlation coefficient trends were also analysed for the identification of the possible uses and weaknesses of NDVI in the depiction of natural water variability. Visu-

alization of the quantitative and spatial trends of NDVI, and a refinement of the identified relationships was achieved using GIS map algebra and overlay tools.

The data were analysed on the basis of a calendar rather than a vegetative year, which starts the month following that one with the minimum NDVI. This is because for the Lake Victoria basin, the driest months can be any of the months in the two dry seasons, yet a minimum NDVI only occurs in August in any of the years (see Fig. 6b). For seasonal analysis, the data were classified over three monthly intervals with the onset of the first dry season 
being December of the preceding year, and ending in February. This is based on the known local pattern of rainfall in the Victoria Basin as indicated in Fig. 6a. The seasons are typically: Dec-Feb (dry), Mar-May (very wet), JunAug (dry) and Sep-Nov (wet). This pattern has been used in many studies, for example, an analysis of drought severity by Awange et al. (2007).

Exploratory Data Analysis: The water levels tend to be normaly distributed. To determine years that require further analysis, the severity in the variability of water levels over annual time scales was depicted using the percentage of normal (PN) (Eqn. 8). The monthly mean levels $\left(X_{M}\right)$ were averaged to give annual mean levels $\left(X_{A}\right)$ for each of the years (Eqn. 6). These were then used to compute the long-term annual mean $\left(X_{30}=11.38\right)$ for a thirty year period (Eqn. 7). The PN values from Eqn. 8 provide the ranking of the years in terms of water level drops (Fig. 5). The normal water level is considered to be $X_{30}$ with a PN value of $100 \%$. Above this are years of greater than normal water levels, while below are those reflecting water stress. Annual and long-term means are given as

$$
X_{A}=\sum X_{M} / 12
$$

and

$$
X_{30}=\sum X_{A} / N
$$

where $\mathrm{N}$ is the number of years considered, in this case 30 years (1976-2005). Using Eqns. 6 and 7, one obtains the percentage of normal (PN) as

$$
P N=\left(X_{A} / X_{30}\right) \times 100
$$

FIGURE 5 
It can be seen from Fig. 5 that the water levels were above or near normal for most years and consistently so between 1976 and 1984. However, they are almost consistently below the normal between 1992-2005, except for 1998 and 1999. In the East African region, the El Nino-Southern Oscillation (ENSO) rains are known to have started in late October 1997, but intensified during most of 1998. In early 1999, only moderately high rainfall was experienced as an extended effect of the ENSO rains. Thus, the observed high water levels in 1999 appear to be a result of the higher precipitation in 1998. It is then seen that the water level sharply fell between 2002 and 2005.

The annual variation of these variables for a sample of years (two high precipitation years 1991, 1999, one normal 2003, and one low 1994) were compared using their mean monthly values as shown in Fig. 6a, 6b and 6c. To compare the water level variability with NDVI, PN values for NDVI were compared with corresponding PN values for water levels for the common years 1987-2003 (Fig. 6d).

\section{FIGURE 6}

Figures $6 \mathrm{a}$ and $6 \mathrm{~b}$ suggest a seasonal response of NDVI to precipitation. Using the monthly means, the correlation coefficients $(r)$ between NDVI and precipitation for 1991, 1994 and 2003 with no time lag are 0.39, 0.78 and 0.19 , respectively. With rainfall proceeding the NDVI by one-month (i.e., one-month NDVI lag), on average, higher values of $r$ were obtained, with $r$ equal to $0.45,0.55$ and 0.37 , respectively. However, with a two-months lag, this association is almost non existent, with $r$ values of $0.27,0.07$ and 0.03 , respectively. It can also be seen that the 2003 precipitation is much lower 
relative to 1991, 1994 and 1999 (Fig. 6a). The significant drop in $r$ values for 1994 when considering time lags is due to the relatively much higher rainfall resulting in an NDVI lag that does not affect the correlation values. This leads to the proposal that considering time lags is only appropriate for moderate to drought years.

Hence, as expected, there appears to be a good localized association between rainfall and NDVI in the Lake Victoria catchment when one considers a one-month time lag, i.e., when rainfall of the preceding month is compared with the NDVI of the current month. There is also the possibility of a direct correspondence between the maximum rainfall and maximum NDVI occurrences in any of the years. However, there is a month difference between an occurrence of minimum rainfall (Sept) and minimum NDVI (Aug). This may be because NDVI is very sensitive to any slight reduction in rainfall.

Figure $6 \mathrm{c}$ shows that within a given year, the lake's monthly mean water levels vary slightly, as indicated by the amplitudes. This is in contrast to the monthly mean NDVI, which shows comparatively larger variations in its small values (Fig. 6b). The smaller gradients in Fig. 6c compared to the sharper ones in Fig. $6 \mathrm{~b}$ are a further indication of the sensitivity of NDVI to precipitation, as opposed to the delayed response of water levels to surface run off from the catchment. The water levels are maximum in May-June following the March-April-May rainfall season (e.g., Awange et al. 2007), whereas maximum rainfall and NDVI are in April-May. Again, there is no direct correspondence between the minimum water level, which is generally between Oct-Dec, and the minimum rainfall or NDVI (Aug-Sept). Overall, these observations seem to indicate that within a year, NDVI responds faster 
to weather changes than water levels.

The comparison of PN values computed from Eqn. 8 (Fig. 6d) shows that over annual time scales, NDVI may be less sensitive to weather patterns than water levels, whose PN trend is more sinusoidal than NDVI. Their sinusoidal curves appear to be similar in configuration but with opposite gradients. However, there is almost no association $(r=0.11)$ between the annual mean NDVI and annual mean water levels. Considering annual mean water levels lagging annual mean NDVI by one year, there is still a poor correlation $(\mathrm{r}=-$ 0.26), which increases to -0.29 for a two year lag. With NDVI lagging the water levels, there is only a very small association $(r=-0.23)$.

Co-variability trend analyses were then performed, firstly using NDVI in its primary 'raw' form and water levels; and then using the NDVI derived drought metrics. The metrics are the standardized or normalized NDVI (Eqn. 4). Data anomalies and temporal differences were also used. The annually integrated NDVI (AINDVI) trend (i.e., the sum of mean monthly NDVI in a given year) was derived for use as a proxy indicator of precipitation patterns. An attempt was made to refine the sensitivity of the NDVI/water level covariability trend based on a suggested threshold AINDVI.

AINDVI Image Analysis: To interpret the AINDVI spatial trend, sample AINDVI images for the years 1988, 1992, 1996, 1997, 1998 and 2003, which are typically representative of the inter-annual precipitation patterns were extracted. Figure 7a shows the distribution of NDVI for a sample high precipitation year (1988) and a drought year (1997). Just like the primary source NDVI images, the distribution of AINDVI within the pixels is typically normal, reaffirming the heterogeneous vegetation at $8 \mathrm{~km}$ spatial resolution. It 
appears to emphasize that due to the low spatial resolution of the GIMMS NDVI, no large distinct areas of homogenous vegetation cover that would affect the study results can be identified.

Iterative process: Improving the NDVI / water level sensitivity using the AINDVI Spatial Pattern: The North-Western and North-Eastern parts of the lake catchment were found to have higher AINDVI. Considering that the water level/NDVI relationship is very sensitive to small changes in AINDVI (precipitation), while ANDVI still tends to have an upper limit for the case of high correlations, the NDVI images were further masked. The local upper threshold AINDVI was obtained by comparing the local AINDVI variability curve with the observed NDVI / water level $r$ values. To improve on the association, image areas with AINDVI higher than the upper threshold, here set to 6.4, were masked out to provide refined $\mathrm{CAM}(\mathrm{Y})$ images (Fig. 7b). With the exception of 1991, 1996 and 1998 (Fig. 8a), the local upper threshold AINDVI for obtaining good correlations $(r>0.5)$ is about 6.46 (see Fig. 8c). This further masking was based on the 1988 AINDVI image which had the highest AINDVI in the dataset (see Fig. 8c). It provided a refined CAM as the catchment area with AINDVI pixel values less than 6.4 and masked the NDVI pixels that had a high probability of having values greater than the upper threshold. Repetitive masking of higher outlier AINDVI pixels was carried out as outlined in Fig. 7c.

FIGURE 7 


\section{Results and Discussions}

Raw NDVI and water level covariability: The strength of association between water level and raw NDVI variability was assessed based on temporal lags. Zero, one and two-months lags were used with NDVI lagging the water levels (Table 1, Fig. 8a). For a given year, the one-month lag, for example, means that the mean NDVI of December was associated with the mean water level of the following January. Within a year there is generally a low association between the monthly mean NDVI and the corresponding monthly mean water levels. However, with NDVI lagging the water levels by one or two-months, higher correlations were obtained, except for the years 1988 and 1997 for the two-months lag. The year 1988 does not indicate any association between its NDVI and water level at all, while for 1997, contradictory results are shown with very low association for the two-months lag, but good associations for the zero and one-month lags are realized. However, there were two extreme weather patterns in 1997, with drought occurring throughout much of the year, with exceptionally high ENSO rainfall from October onwards (FAO, 1998). The observed low correlations in 1998 appear to be indicative of the peak of heavy ENSO rains.

The reverse was also tested, i.e., water levels lagging NDVI by one month (Fig. 8b). The hypothesis was that current rainfall can only be reflected in NDVI as cumulated moisture over time, but it should be directly observable in water levels as a summation of direct rainfall over the lake surface and surface run off. This may be false because relatively low correlations (Fig. 8b) were obtained, especially when compared to those in Fig. 8a.

On average, when the NDVI of the preceding month is associated with 
Table 2: Correlations between NDVI and water levels for the lags of zero, one, and two months.

\begin{tabular}{|c|c|c|c|}
\hline Year & 0 -lag & 1-month lag & 2-months lag \\
\hline 1987 & -0.08 & & \\
1988 & -0.05 & -0.25 & -0.40 \\
1989 & 0.52 & 0.74 & 0.68 \\
1990 & 0.18 & 0.45 & 0.59 \\
1991 & 0.07 & 0.33 & 0.33 \\
1992 & 0.18 & 0.55 & 0.48 \\
1993 & 0.63 & 0.88 & 0.98 \\
1994 & 0.44 & 0.68 & 0.60 \\
1995 & 0.28 & 0.42 & 0.45 \\
1996 & -0.32 & 0.12 & 0.45 \\
1997 & 0.88 & 0.63 & -0.19 \\
1998 & -0.01 & 0.23 & 0.54 \\
1999 & 0.54 & 0.81 & 0.62 \\
2000 & 0.65 & 0.89 & 0.76 \\
2001 & 0.57 & 0.81 & 0.66 \\
2002 & 0.50 & 0.78 & 0.67 \\
2003 & 0.37 & 0.54 & 0.38 \\
\hline
\end{tabular}


water levels of the current month (one-month lag), better correlations were obtained (average $r=0.54$ ) than for a two-months lag (average $r=0.49$ ). In addition, we calculated long-term monthly means of NDVI and water levels across the study years. Their correlation analysis appeared to confirm that one-month lag $(r=0.81)$ is better than no lag $(r=0.47)$ or two-months lag $(r=0.73)$ for modelling the predictability of water levels from NDVI.

Use of AINDVI variability trend: To explain the observed variations in Fig. 8a, the annually integrated NDVI (AINDVI) was computed as the sum of the monthly mean NDVI for each of the years (Fig. 8c). Figures 8a and 8c indicate that with the exception of 1997 (two-months lag), at low AINDVI, the $r$ values tend to be higher. When the AINDVI was analysed against the $r$ values of Fig. 8a, good negative correlations were obtained for zero month $(r=-0.59)$ and one-month lags $(r=-0.50)$, but poor correlation $(r=-0.01)$ for the two-months lag. The later is possibly diluted by the outlier character of 1997. This observation equally applies when Fig. 8b is compared to Fig. 8c.

The range of variability of AINDVI is quite small (6.1 - 6.6) as indicated in Fig. 8c, however, this small variation still produces marked differences in the NDVI/ water level association observed in Fig. 8a. This means that the use of NDVI in the depiction of water levels for a given year is very sensitive to the AINDVI and therefore to the annual precipitation. The good positive correlations at lower precipitation (low AINDVI, e.g., Figs. 8a and $8 \mathrm{c}$ ) indicate that both the water levels and NDVI are not only sensitive to low precipitation, but they respond to it more than to excessive rainfall. Even then, NDVI responds to a reduction in precipitation much faster than the water levels. This explains the better correlations at the one-month to 
two-months' lags.

For higher annual precipitation, there are weaker associations between NDVI and water levels. A case in point is 1998, owing to the ENSO rains. Although, this was the case in 1998, one would expect that there was much more rainfall in 1988, 1989, 1991, 1995, and 1996 as inferred from their higher AINDVI. However, NDVI saturates at higher precipitation, as seen in 1998. High NDVI is associated with sufficient soil moisture content rather than total water in the system which, when in excess, causes water logging and subsequently stagnation of photosynthetic activity. Therefore, these years appear to have had optimum moisture rather than excessive rainfall. In addition, the commissioning of the Kiira dam does not appear to be the cause of the poor associations in 1996, but rather it is the relatively high rainfall that was just enough to lead to higher AINDVI values than in 1998.

One would also expect poorer correlations in 1999 than in 1998 as suggested by the higher AINDVI in 1999, but the opposite is observed. This is because the ENSO rains peaked in 1998, and continued only to the beginning of 1999. Therefore, there was no NDVI saturation in 1999, but rather the moisture delivered at the start of the year and the moderate rainfall thereafter appears to have sustained the vegetation vigour throughout most of the year. Hence, the higher AINDVI values in 1999 (Fig. 8c) than in 1998, while still producing higher $r$ values (Fig. 8a).

Generally, poor correlations were obtained when water levels were lagged behind NDVI in the analyses (Fig. 8b). This enhances the argument that NDVI responds more sensitively to weather patterns than do water levels. In addition, NDVI responds to cumulative moisture (rainfall) whereas the 
Table 3: Refined correlations following the suggested iterative process (Fig. 7c).

\begin{tabular}{|c|c|c|c|c|c|c|}
\hline & AINDVI & $\begin{array}{c}\text { Refined } \\
\text { AINDVI }\end{array}$ & $\begin{array}{c}\text { \% Change } \\
\text { AINDVI }\end{array}$ & $r$ & $r$ & $\begin{array}{c}\text { Refined } \\
\%\end{array}$ \\
\hline 1988 & 6.6 & 5.62 & 15 & -0.25 & -0.34 & 36 \\
1991 & 6.39 & 5.62 & 12 & 0.33 & 0.32 & 3 \\
1996 & 6.51 & 5.54 & 15 & 0.12 & 0.2 & 67 \\
1998 & 6.42 & 5.62 & 12 & 0.23 & 0.37 & 61 \\
\hline
\end{tabular}

Lake Victoria water level only instantaneously responds to rainfall, with a time delay in its response to runoff. If the cumulative effect of rainfall in the specific days were to be reflected in the monthly mean water levels, the water levels would have good correlations with the NDVI of the next month(s) (perhaps at even no lag), and also at relatively higher, but nonNDVI saturating amounts of rainfall (e.g., 1996). This in essence would agree with the observations of Nicholson et al. (1990), that rainfall (and therefore water levels) should precede NDVI for better associations. These arguments seem to explain the outlier characteristics of 1988 and 1996, which show no saturation in NDVI (Fig. 8c), but also display low correlations (Fig. 8a).

The sensitivity NDVI/water level association to the AINDVI spatial pattern: The AINDVI refined CAM was used on a sample of CAM(Y) NDVI images for 1988, 1991, 1996 and 1998, which displays a correlation or AINDVI greater than or equal to the upper threshold AINDVI of 6.4 (e.g., 1991). The results are shown in Table 3. In essence, to achieve better models for depicting lake water levels from catchment NDVI, we applied the proposed iterative approach (Fig. 7c). 
FIGURE 8

The variability in the NDVI/water level relationship is well explained by the AINDVI, which is sensitive to changes in precipitation (AINDVI). It was found that masking out NDVI pixels with a higher than the threshold AINDVI value improved the ability of NDVI to depict the water levels, especially in drought conditions. When NDVI pixels with higher than the suggested threshold AINDVI were masked out, the suggested iterative process in Fig. 7c improved the correlations by more than $60 \%$ for 1996 and 1998 (Table 3). For example, for 1996 there is a 15\% reduction in AINDVI leading to a $67 \%$ improvement in the correlation coefficient. However, there is no proportionality in the changes. In 1991 and 1998, there was a 12\% reduction in the AINDVI, but the change in $r$ for 1991 is almost negligible, with a $3 \%$ reduction compared to a $61 \%$ increase for 1998 . This appears to be because the 1991 AINDVI of 6.39 is only slightly below the 6.4. Even then,

the results for 1991 seem to confirm the existence of a localized threshold AINDVI.

One month was identified as the most appropriate time frame for lagging NDVI behind water levels, as shown in Fig. 8a. Therefore, the following analyses are restricted to further understanding the applicability of the onemonth lag using NDVI drought metrics

Using the standardised vegetation index (SVI): The SVI (Fig. 8d) was computed using Eqn. 4, assuming a normal distribution of these variables. The standardisation yields the SVI when the input is NDVI. The correlations between SVI and water levels were very low and yet the fluctuation was 
high. SVI was not found to be a useful direct predictor of water levels. However, its correlation with the standardized water levels (SWL) shown in Fig. 8d to some extent follows the same trend as that of Fig. 8a for the period 1992-2003. In Fig. 8d, the 1998 coefficient indicated in Fig. 8a is attenuated relative to those of 1988 and 1996 that have been amplified. This suggests that the SVI and SWL relationship has the ability to reveal higher than normal rainfall events. For example, in comparison to Fig. 8a, 1998 and 1999 in Fig. 8d are both attenuated proportionately to excess rainfall. The ENSO rains that peaked in 1998 continued to the early months of 1999. Therefore, whereas 1988 and 1996 had lower correlations compared to 1998 and 1999, they did not have higher than normal rainfall, which is a requirement for their optimum NDVI. This seems to support the argument for their relatively higher AINDVI (Fig. 7b). Similarly, abnormal rainfall patterns, and therefore NDVI patterns, appear to have occurred in the years 1989-1992 and 1997. In Fig. 8a, these have good positive correlations, but negative correlations in Fig. 8d. This does not happen for the other years, that similarly show positive correlations in Fig. 8a.

Vegetation condition index (VCI): The aggregated VCI was computed using Eqn. 9, which is synonymous with Eqn. 3, except that monthly mean NDVI was used instead of the pixel values, and the multi-year minimum and maximum NDVI were identified as 0 and 0.999, respectively. These values signify the existence of both bare soils and extremely vigorous vegetation cover types in the catchment. For the Lake Victoria catchment, the VCI is equal to the NDVI (Eqn. 9). Thus, the VCI analyses, results, and interpretations are not different from those of raw NDVI. The aggregated VCI is 
computed as

$$
V C I=N D V I / 0.999
$$

Since the functioning of the VCI is similar to that of the green vegetation fraction $\left(F_{g}\right)$ in Eqn. $(2)$, its global minimum and maximum NDVI values were used to compute two sets of $F_{g}$ using 0.04 and 0.52 (Gutman and Ignatov, 1998) and 0.2 and 0.7 (Carlson and Ripley, 1997), respectively. However, more than $50 \%$ of the mean monthly NDVI values are greater than 0.52. Thus, for the Gutman and Ignatov (1998) values, more than $50 \%$ of the obtained $F_{g}$ values were greater than unity. Within the context of the fractional cover $F c=F_{g}^{2}$, these values were unrealistic. However, the Carlson and Ripley (1997) values fitted the NDVI dataset and provided a correlation pattern shown in Fig. 9a, which is similar to Fig. 6d. Thus, like the VCI, the analyses and use of the $F_{g}$ give results that are also exactly the same as those of the raw NDVI, with only a scaling effect on the NDVI values.

Use of NDVI Anomaly (NDVIA): The NDVI Anomaly (NDVIA) in Eqn. (5) was used firstly with the raw water levels and then with similarly computed water level anomalies. In both cases, the NDVIA lagged the water levels by one-month. The NDVIA has a weak ability to depict the water levels as indicated by its generally poor and very noisy trend in Fig. 9b. The analysis of both anomalies resulted in a pattern (Fig. 9c) similar to that found using the SVI (Fig. 8d) and therefore other relatable patterns (Fig. 8a). Like the SVI, the NDVIA equally has the ability to attenuate the NDVI/water level co-variability as affected by higher or lower than expected rainfall events (Fig. 9c).

In addition, the annual mean water levels anomaly (AMWLA) and annual 
mean NDVIA (AMNDVIA) were computed as the means of their respective monthly anomalies for each of the study years. Their variabilities are shown in Figs. 9d and 9e respectively. Unlike the AMWLA (Fig. 9d), the variability in AMNDVIA, shown in Fig. 9e, does not explain any of the NDVI and water level trends.

FIGURE 9

Combined use of anomalies, SVI/SWL co-variability and AINDVI: The AMWLA inter-annual variability (Fig. 9d) generally followed the correlation variability in Fig. 8a, especially from 1991 onwards, with some discrepancies, namely that it only peaked in 1994, whereas in Fig. 8a, the peaks were in 1993 and 2000. Even then, it correctly does so in the years 1991-1997, but falls short of the same in the other years, for example, 1998-2003, that are very much attenuated. Like the SVI, the anomaly trend appears to have the ability to distinguish years with very anomalous water levels, despite a strong correlation with NDVI. For example, 1998 is a known ENSO year and it is very well depicted as being more anomalous than 1996, which on the the other hand shows a lower correlation in Fig. 8a than 1998.

The trend also clearly isolates 1989, 1991, 1998, and 1999 as having higher than normal water levels. Thus the hypothesis of depicting higher than normal rainfall events using the SVI/SWL trend indicated for 1989 -1992 and 1997-1999 as earlier suggested may be valid. A typical example is 1997, where there was drought for most of the year $(\mathrm{FAO}, 1998)$, with lower than normal water levels (Figs. 5 and 9d) and the lowest AINDVI (Fig. 8c). However, Fig. 8d does not indicate it as being a very dry year. This is because of 
the short occurrence of extremely heavy ENSO rainfall from November 1997. Thus, this mixture of severe drought and short heavy rains explains why it is less attenuated in Fig. 8d than 1989-1992, 1998 and 1999, which were much wetter as inferred from their higher AINDVI values (Fig. 8c).

The importance of the 1997 trend can be stressed by comparing it with 1994. The AINDVI for 1997 is much lower (Fig. 8c) and has on average higher water levels (Fig. 5) with a lower positive anomaly (Fig. 9d), again a result of the short but heavy ENSO rains that contributed to its higher average water level compared to 1994. However, there was long dry spell in 1997 that severely reduced its vegetation vigour (Fig. 8c). This appears to confirm the fact that NDVI is more sensitive to drought than are the water levels. If the precipitation in 1997 was sufficiently low throughout the year, as it appears to have been in 1994 which has a higher AINDVI yet lower water levels, the 1997 AINDVI would not be very anomalous in contrast to its water levels (Fig. 6d). This confirms the existence of a mixture of long severe drought and short extremely heavy rainfall during 1997.

These observations point to the use of the SVI/SWL association in conjunction with the AINDVI and the AMWLA in isolating years of higher than expected rainfall, regardless of there being no saturation in NDVI for a given year, e.g., 1989-1992, and for cases where a year may in fact be classified as a drought year, e.g., 1997. This also emphasizes the fact that both the water levels and the NDVI are more sensitive to drought than excessive rainfall. This is explained by the good association that is indicated for 1997 (Fig. 8a) in contrast to some of the wetter years, e.g., 1990-1992, 1998 and 1999. These indicate a lower association between the NDVI and water levels, therefore, 
any effort towards a practical use of NDVI/water level correlations may be fruitless.

It also seems that the anomaly trend has the ability to highly attenuate years of possible anthropogenic influence on water level variation (2000- onwards). This hypothesis may be true because the years 1992-1997, which are also known to depart from normal (Fig. 9d), try to maintain their configuration of Fig. 8a and yet the years from 2000 are highly attenuated in Fig. $9 \mathrm{~d}$.

Use of differenced image NDVI: Inter-monthly NDVI differences in water levels and in NDVI were analysed (Fig. 10). The differences in NDVI and in water levels from month to month were computed for each of the years (note, the January differences were computed as differences from December of the preceding year). Their correlations were computed at zero and one-month lags. These are, on average, reasonably high, but noisy. They appear to mimic their corresponding patterns in Fig. 8a, especially for the later years, i.e., 1996 onwards (Fig. 10a).

As shown in Fig. 10a, both lags are very noisy, but on average provide almost the same good correlations. Their average $r$ values are 0.53 and 0.49 for the zero and one-month lag, respectively. Thus, the observed patterns in 1996 and 1998 can still be explained in terms of higher rainfall as depicted by the AINDVI (Fig. 8c).

The use of one-month lag in Fig. 10a is well explained by the AINDVI $(r=-0.59)$. This is unlike the zero lag which, despite having a higher average $r$ value, has a correlation with AINDVI of -0.46. However, these apparent higher associations may only be so because 1988 attained positive correlations 
of 0.65 and 0.23 for the zero and one-month lags, respectively (Fig. 10a). Despite the 1988 ( $r=-0.25)$ value, generally, the co-variability of the raw NDVI and water levels at one-month lag shown in Fig. 8a (average $r=0.54$ ) is still better than from the differences and is still well explained by the AINDVI $(r=-0.50)$.

Example of regression fits: Regression fits for NDVI lagging water levels using examples of moderate precipitation years, 1993 and 2000, show a good linear trend. Similarly, long-term monthly means of the two datasets computed for the full study period show that up to $80 \%$ (see the coefficient of determination $R^{2}$ values) of the association between the NDVI/water levels can be explained by simple linear fits (Figs. 10b, 10c and 10d).

FIGURE 10

\section{Conclusions}

This study used aggregated NDVI values and has demonstrated that for the Lake Victoria catchment basin:

1. NDVI can be used in depicting the expected natural trends of its water levels.

2. NDVI can identify suspicious, possibly anthropogenic variations by isolating drought episodes. This is especially so when considering a onemonth temporal lag of water level with respect to NDVI. It appears to be mostly applicable in normal rainfall and drought years, during which time NDVI is more sensitive to low precipitation than the water levels are. 
3. The use of NDVI can be iteratively improved upon by considering the catchment specific threshold annually integrated NDVI (AINDVI). As a drought metric, NDVI governs its suggested use by acting as a surrogate for identifying high rainfall years when it cannot be appropriately used. It can then be used to decipher abnormal precipitation trends by the use of the water level and NDVI anomalies, namely the AINDVI, SVI and AMWLA trends. We thus propose this iterative approach.

These conclusions may be useful for developing early warning mechanisms for Lake Victoria water management. Indeed, one should foresake using NDVI in years when the predicted AINDVI is greater than the suggested local threshold. These are years with plenty of rainfall, hence there would be no stress on the lake's waters, and yet, as explained, the NDVI / water level relationships do not generally hold. These mechanisms may function well in advance, given that there are possibilities of forecasting NDVI and therefore AINDVI. However, further analysis is recommended using high resolution imagery and undertaking analyses using pixel-specific NDVI, rather than the aggregate catchment NDVI.

\section{Acknowledgment}

The Authors thank the Editor-in-Chief, G. P. Tsakiris and the two anonymous reviewers for their comments and suggestions during the review period of the manuscript. JLA acknowledges the financial support of the Alexander von Humbodlt Foundation (Ludwig Leichhardt's Memorial Fellowship), The Institute for Geoscience Research (TIGeR), and a Curtin Research Fellowship. He is grateful for the warm welcome and the conducive working 
atmosphere provided by his host Prof. Heck at the Geodetic Institute, Karlsruhe Institute of Technology (KIT). The authors are grateful to E. Forootan of Bonn University for providing the tide gauge data and Fig. 3. They acknowledge the datasets used in this work and are grateful to Dr. Kevin Fleming for proof reading the manuscript, but take the responsibility of any errors. This is a TIGeR publication No. 396.

\section{References}

Anyamba A, Tucker CJ, and Eastman JR (2001) NDVI anomaly patterns over Africa during the 1997/98 ENSO warm event, International Journal of Remote Sensing 22 (10): 1847 - 1859. doi: 10.1080/01431160010029156

Anyamba A, Tucker CJ, Mahoney R (2002) From El nino to La nina: Vegetation response patterns over East and Southern Africa during the 1997-2000 period. Journal of Climate 15 (21): 3096-3103. doi: 10.1175/1520-0442(2002)015¡3096:FENOTL¿2.0.CO;2

Awange JL, Ogalo L, Bae K-H., Were P, Omondi P, Omute P, Omulo M (2008) Falling Lake Victoria levels: Is climate a contributing factor? Climate Change, 89: 281-297. doi: 10.1007/s10584-008-9409-x

Awange JL, Aluoch J, Ogallo LA, Omulo M, Omondi P (2007) Frequency and severity of drought in the Lake Victoria region, Kenya and its effects on food security. Climate Research 33 (2): 135-142.

Awange JL, Ong'ang'a O (2006) Lake Victoria: ecology resource and 571 environment. Springer, Berlin. 
Baret F, Guyot G (1991) Potentials and limits of vegetation indices for LAI and APAR assessment. Remote Sensing of Environment 35 (2/3): 161-173. doi:10.1016/0034-4257(91)90009-U

Bayarjargal Y, Karnieli A, Bayasgalan M, Khudulmur S, Gandush C, Tucker CJ (2006) A comparative study of NOAA-AVHRR derived drought indices using change vector analysis. Remote Sensing of Environment 105(1): 9-22.

Becker M, LLovel W, Cazenave A, Güntner A, Crétaux J-F (2010) Recent hydrological behavior of the East African great lakes region inferred from GRACE, satellite altimetry and rainfall observations. C. R. Geoscience 342: 223233. doi:10.1016/j.rse.2006.06.003

Benada JR (1997) TOPEX/POSEIDON User's Handbook. Technical report, Jet Propulsion Laboratory, California Institute of Technology Generation B (MGDR-B) Version 2.0.

Birkett CM (1995) The contribution of TOPEX/POSEIDON to the global monitoring of climatically sensitive lakes. Journal of Geophysical Research Oceans 100(12): 25,179-25, 204. doi:10.1029/95JC02125

Camberlin P, Martiny N, Philippon N, Richard Y (2007) Determinants of the interannual relationships between remote sensed photosynthetic activity and rainfall in tropical Africa. Remote Sensing of Environment 106 (2): 199-216. doi:10.1016/j.rse.2006.08.009

Carlson TN, Ripley DA (1997) On the relation between NDVI, fractional vegetation cover, and leaf area index. Remote Sensing of Environment 
62 (3): 241-252. doi: http://dx.doi.org/10.1016/S0034-4257(97)001041

Charon B, Reynolds C (2005) Anew remote sensing tool for water resources management.

http://www.pecad.fas.usda.gov/cropexplorer/global_reservoir/index.cfm (Accessed March 21, 2006).

Charon B, Brad D (2004) Anew remote sensing tool for water resource management. Earth Observation Magazine 13 (6).

http://www.eomonline.com/Common/Archives/2004octnov/ (Accessed April 29, 2006).

Chen L, Qian X, Shi Y (2011) Critical Area Identification of Potential Soil Loss in a Typical Watershed of the Three Gorges Reservoir Region. Water Resource Management 25(13): 3445-3463, doi: 10.1007/s11269011-9864-4

Chilar J, Chen JM, Li Z, Huang F, Latifovic R, Dixon R (1998) Can interannual land surface signal be discerned in composite AVHRR data? Journal of Geophysical Research 103: 23163-23172. doi:10.1029/98JD00050

Cretaux JF, Birkett C (2006) Lake studies from satellite radar altimetry. Comptes Rendus Geosci., 338 (14/15): 10981112. doi:10.1016/j.physletb.2003.10.071

FEWS NET (Famine Early Warning Systems Network). 2007. Africa data dissemination service. http://earlywarning.cr.usgs.gov/adds/index.php (Accessed March 1, 2008). 
FAO (Food and Agriculture Organization). 1998. Food supply situation and crop prospects in Sub Saharan Africa: Africa report, no. 1/98. Rome Italy: FAO/GIEWhttp://www.fao.org/DOCREP/004/W8261E/w8261e03.htm (Accessed Feb 28, 2008).

Fu L-L, Christensen E, Yamarone C Jr., Lefebvre M, Escudier M, Menard P, Dorrer Y (1994) TOPEX/POSEIDON Mission Overview. http://hdl.handle.net/2014/34628.

Gontia NK, Tiwari KN (2010) Estimation of Crop Coefficient and Evapotranspiration of Wheat (Triticum aestivum) in an Irrigation Command Using Remote Sensing and GIS. Water Resource Management 24(7): 1399-1414, doi: 10.1007/s11269-009-9505-3

Gutman GG (1999) On the use of long-term global data of land reflectances and vegetation indices derived from the advanced very high resolution radiometer. Journal of Geophysical Research 104: 6241-6255. doi:10.1029/1998JD200106

Gutman G, Ignatov A (1998) The Derivation of the green vegetation fraction from NOAA/AVHRR data for use in numerical weather prediction models. International Journal of Remote Sensing 19 (8): 1533 - 1543. doi:10.1080/014311698215333

Hatfield JL, Prueger JH, Kustas WP (2004) Remote sensing of dryland crops. In Remote sensing for natural resources and environmental monitoring: Manual of Remote Sensing. 3rd ed., vol. 4. ed. Ustin, S., 531-568. New Jersey: John Wiley \& Sons. 
Hay SI, Snow RW, Rogers DJ (1998) Predicting malaria seasons in Kenya using multi temporal meteorological satellite sensor data. Transactions of the Royal Society of Tropical Medicine and Hygiene 92 (1): 12-20

Kastens JH, Kastens TL, Kastens DLA, Price KP, Martinko EA, Lee R (2005) Image masking for crop yield forecasting using AVHRR NDVI time series imagery. Remote Sensing of Environment 99 (3):341-356. doi: 10.1016/j.rse.2005.09.010.

Kiage LM, Walker ND (2009) Using NDVI from MODIS to Monitor Duckweed Bloom in Lake Maracaibo, Venezuela. Water Resource Management 23: 1125-1135, DOI 10.1007/s11269-008-9318-9

Kogan FN (1997) Global drought watch from space. Bulletin of the American Meteorological Society 78 (4): 621-636.

doi: 10.1175/1520-0477(1997)078;0621:GDWFS¿2.0.CO;2

Kull D (2006) Connection between recent water level drops in Lake Victoria, dam operations and drought: Technical Report. International River Network. http://www.irn.org/programs/nile/

Liang S (2004) Quantitative remote sensing of land surfaces. New Jersey: Wiley \& Sons.

Liu WT, Negrón Juárez RI (2001) ENSO drought onset prediction in northeast Brazil using NDVI. International Journal of Remote Sensing 22 (17): 3483 - 3501. doi:10.1080/01431160010006430 
McKee TB, Doesken NJ, Kleist J (1993) The relationship of drought frequency and duration to time scales. Preprints, 8th Conference on Applied Climatology, January 17-22, 1993. Anaheim, CA. http://scholar.google.com/scholar?

Mendicino G, Versace P (2007) Integrated Drought Watch System: A Case Study in Southern Italy. Water Resource Management 21(8): 14091428, doi: 10.1007/s11269-006-9091-6

McVicar TR, Jupp DLB (1998) The current and potential operational uses of remote sensing to aid decisions on drought exceptional circumstances in Australia: A review. Agricultural Systems. 57 (3): 399-468. doi:10.1016/S0308$521 \mathrm{X}(98) 00026-2$

Nicholson SE, Davenport ML, Malo AR (1990) A comparison of the vegetation response to rainfall in the Sahel and East Africa, using normalized difference vegetation index from NOAA AVHRR. Climatic Change 17 (2/3): 209-241.

Nicholson SE (2001a) Application of remote sensing to climatic and environmental studies in arid and semi-arid lands. Geoscience and Remote Sensing Symposium, 2001, July 9-13, 2001. Sydney, NSW: IGARSS '01. IEEE International 3: 985-987. doi: 10.1109/IGARSS.2001.976722

Nicholson SE (2001b) Climatic and environmental change in Africa during the last two centuries. Climate Research 17 (2): 123-144. doi:10.3354/cr017123

Pinzon J, Brown ME, Tucker CJ (2004) Satellite time series correction of orbital drift artifacts using empirical mode decomposition. In Hilbert- 
Huang Transform: Introduction and Applications, Eds. N. Huang, pp. Chapter 10, Part II. Applications. World Scientific Publishing.

Pinzon J, Brown ME (2007) GIMMS NDVI Data description, Global Inventory Mapping and Modelling Studies http://gimms.gsfc.nasa.gov/ndvi/ndvie/GIMMSdocumentation_NDVIe.pdf (Accessed February 28, 2007)

Privette JL, Fowler C, Wick GA, Baldwin D, Emery WJ (1995) Effects of orbital drift on advanced very high resolution radiometer products: Normalized difference vegetation index and sea surface temperature. Remote Sensing of Environment 53(3): 164-171).

Propastin PA (2008) Application of remote sensing Simple model for monitoring Balkhash Lake water levels and Ili River discharges: Application of remote sensing. Lakes \& Reservoirs: Research and Management 2008 13: 7781. doi: 10.1111/j.1440-1770.2007.00354.x

Subash N, Mohan HSR (2011) A Simple Rationally Integrated Drought Indicator for RiceWheat Productivity. Water Resource Management 25(10): 2425-2447. doi: 10.1007/s11269-011-9817-y

Swenson S, Wahr J (2009) Monitoring the water balance of Lake Victoria, East Africa, from space. Journal of Hydrology 370(1-4), 163-176, DOI: 10.1016/j.jhydrol.2009.03.008.

Tucker CJ (1980) Remote sensing of leaf water content in the near infrared. Remote Sensing of Environment 10 (1): 23-32. doi:10.1016/0034-4257(80)900966 
Tucker CJ (1979) Red and photographic infrared linear combinations for monitoring Vegetation. Remote Sensing of Environment 8 (2): 127150. doi:10.1016/0034-4257(79)90013-0

Tucker CJ, Pinzon JE, Brown ME, Slayback D, Pak EW, Mahoney R, Vermote E, El Saleous N (2005) An extended AVHRR 8-km NDVI dataset compatible with MODIS and SPOT vegetation NDVI data. International Journal of Remote Sensing 26 (20): 4485-4498. doi: $10.1080 / 01431160500168686$

USDA/FAS (United States Department of Agriculture, Foreign Agricultural Services) (2007) Global Reservoir Monitor. http://www.pecad.fas.usda.gov/cropexplorer/global_reservoir/index.cfm (Accessed March 21, 2008)

Verdin J, Funk C, Senay G, Choularton R (2005) Climate science and early warning. Philosophical Transactions of the Royal Society B 360 (1463): 2155-2168. doi: 10.1098/rstb.2005.1754 10.1175/1520-0442(2002)

World Resources Institute (2006) Earth trends: The environmental information portal [Image]. http://earthtrends.wri.org/text/water-resources/map300.html (Accessed May 12, 2008).

Yates DN, Strzepek KM (1998) Modelling the Nile Basin under climate change. Journal of Hydrologic Engineering 3(2): 98-108, doi: 10.1061/(ASCE)10840699(1998)3:2(98). 


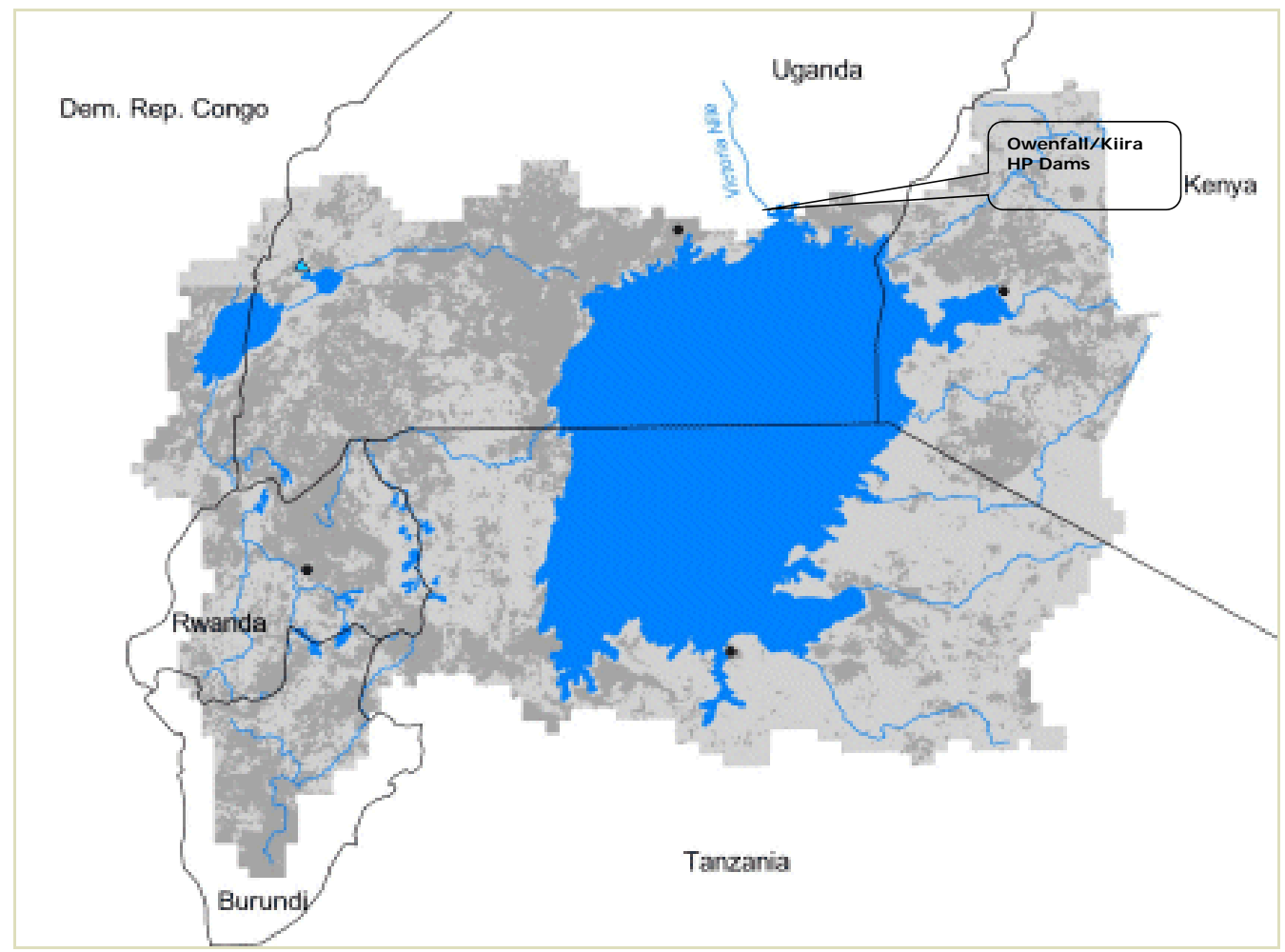

Figure 1: The Lake Victoria Catchment Basin with the Owen Falls hydroelectric dam depicting the position of the Jinja tide gauge station. Source: World Resources Institute (2006). 


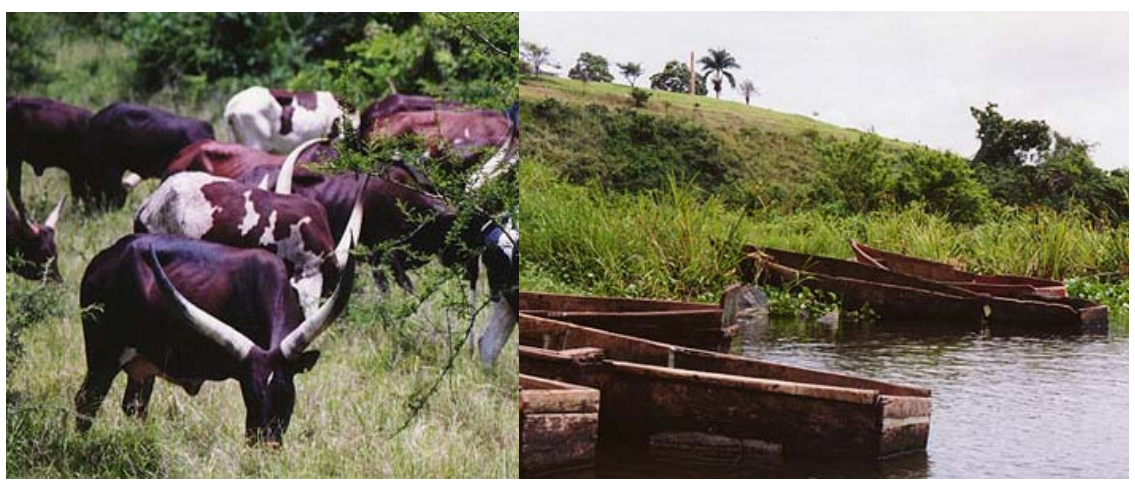

Figure 2: Examples of land use (i.e., cattle farming) and vegetation cover (i.e., shrubs) in the Lake Victoria catchment area. 


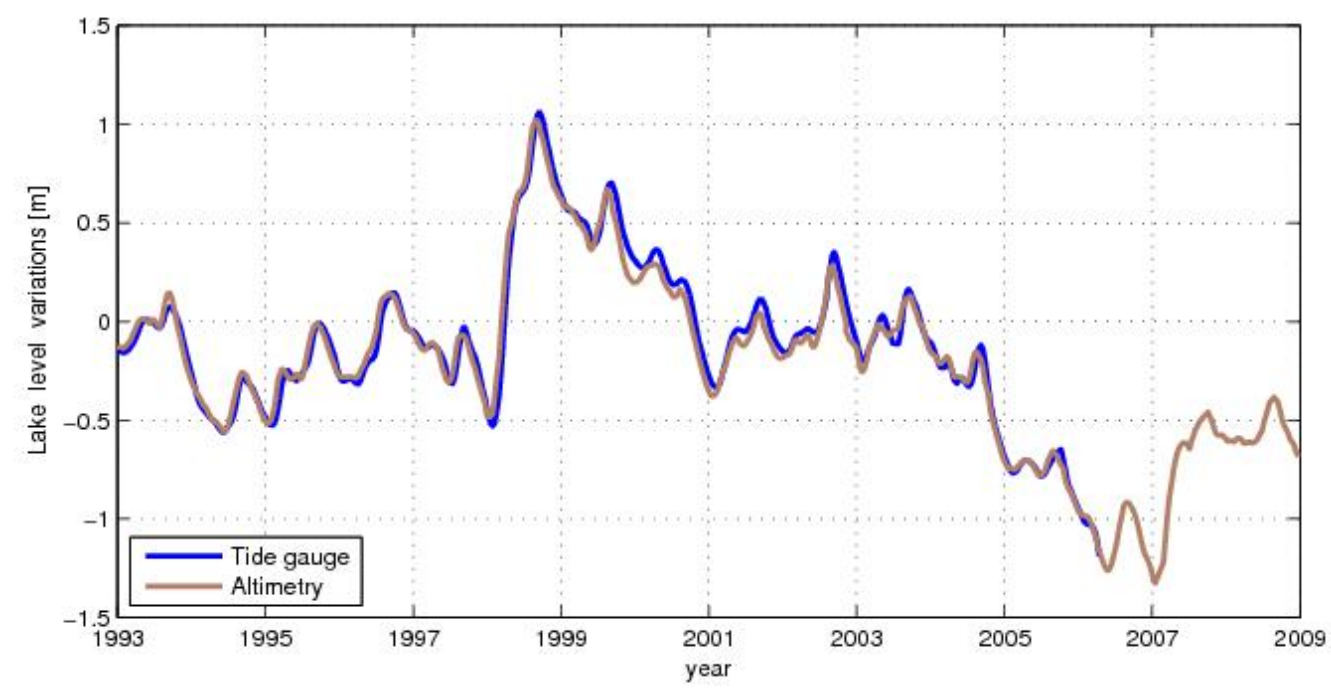

Figure 3: A comparison of water gauge readings, Jinja station, Uganda (near Lake Victoria's outlet), and satellite altimetry water levels (Topex/Poseidon and Jason-1)). 


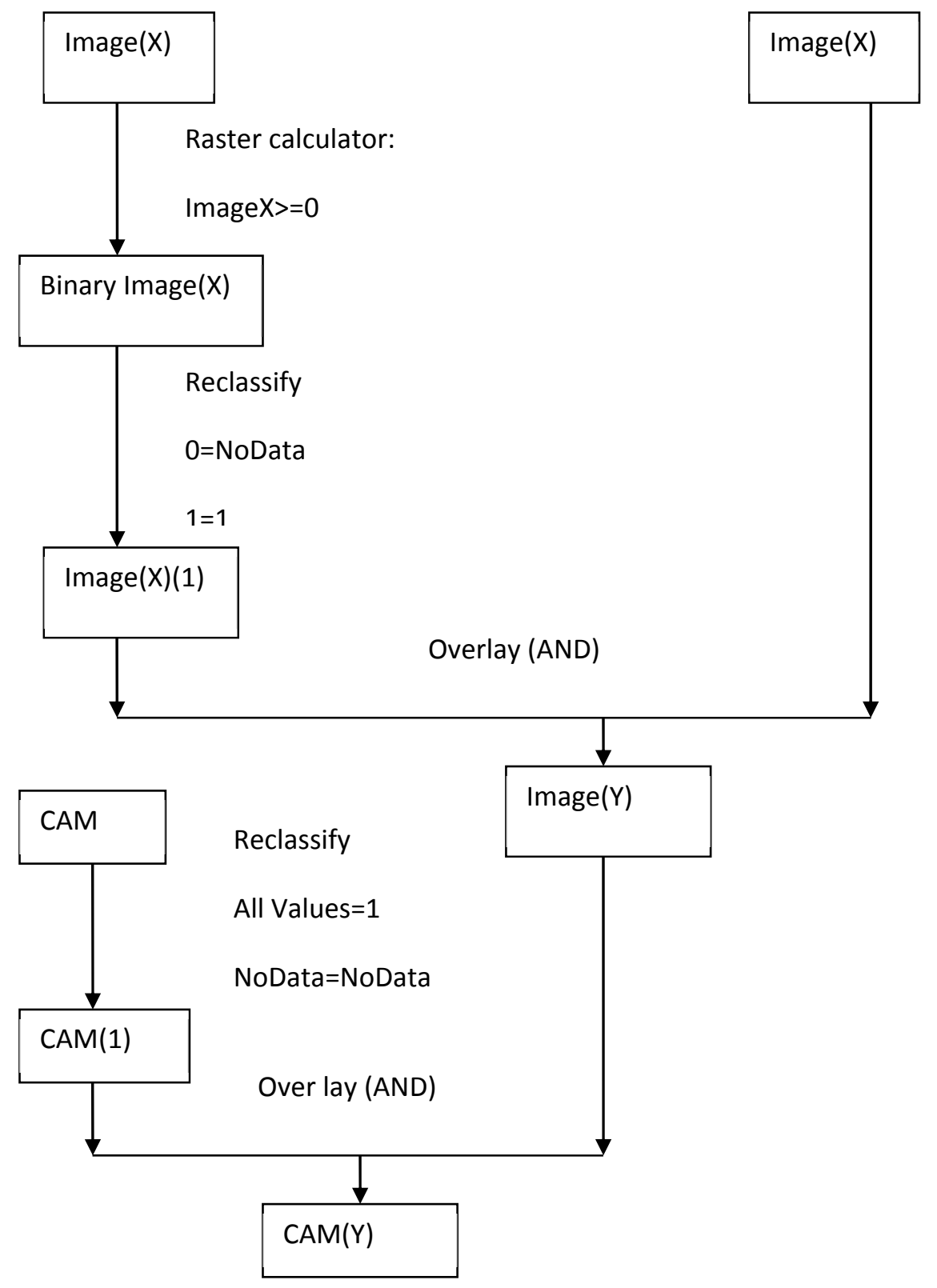




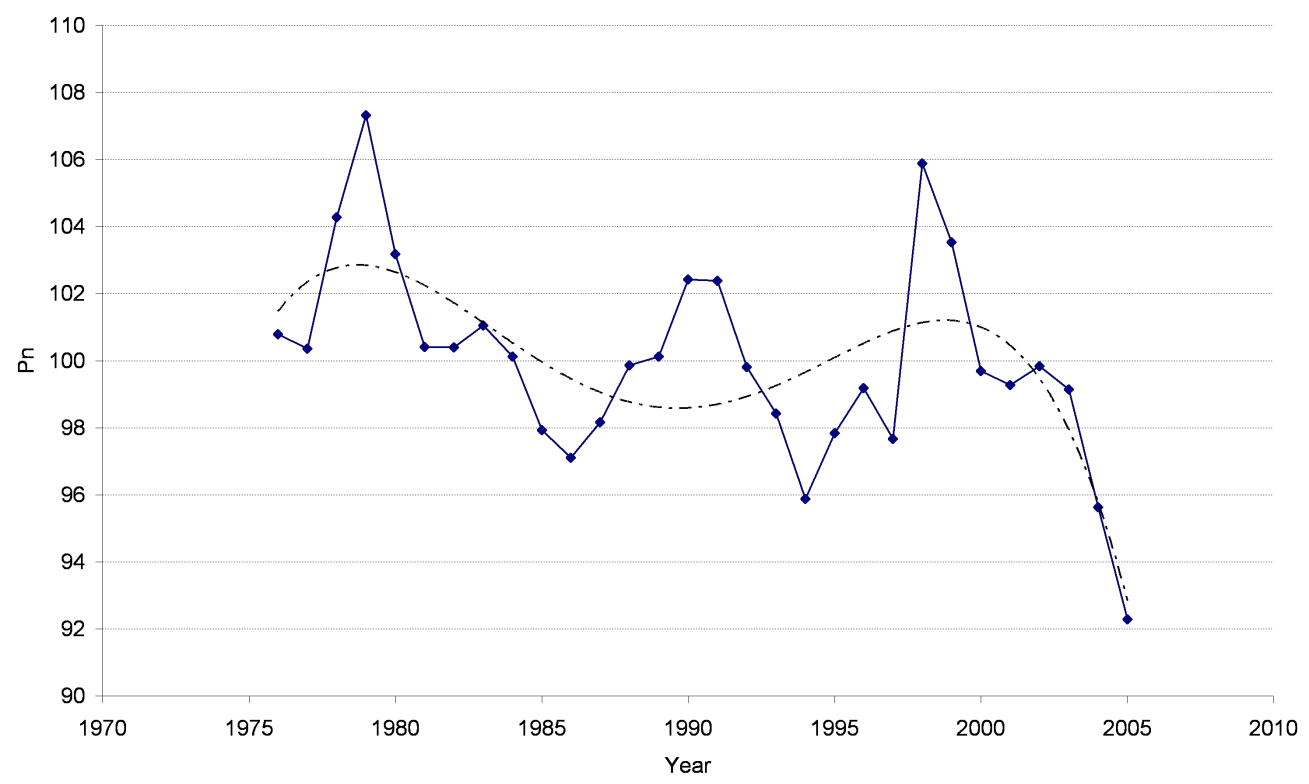

Figure 5: Water level departures from normal (100\%), 1976-2005 (see Eqn. 8). The dashed-dotted lines show a polynomial fit to the data. In general, a declining trend is noticed. 


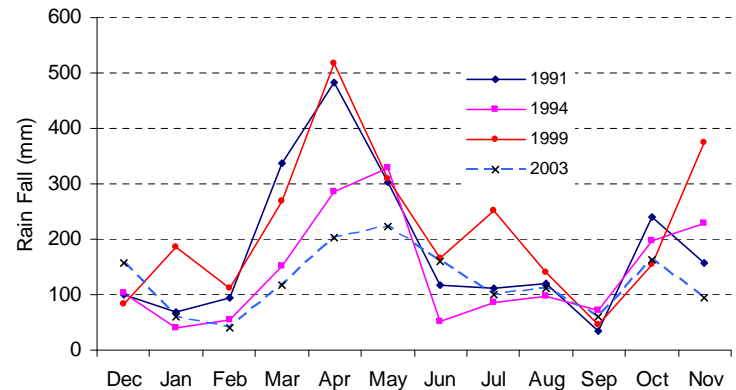

Dec Jan Feb Mar Apr May Jun Jul Aug Sep Oct Nov

(a) Variations in Monthly Mean R/F.

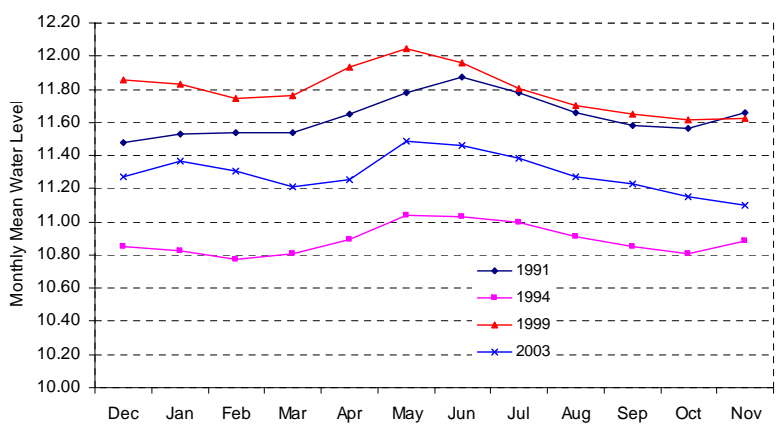

(c) Variation in Monthly Mean Water Level (m).

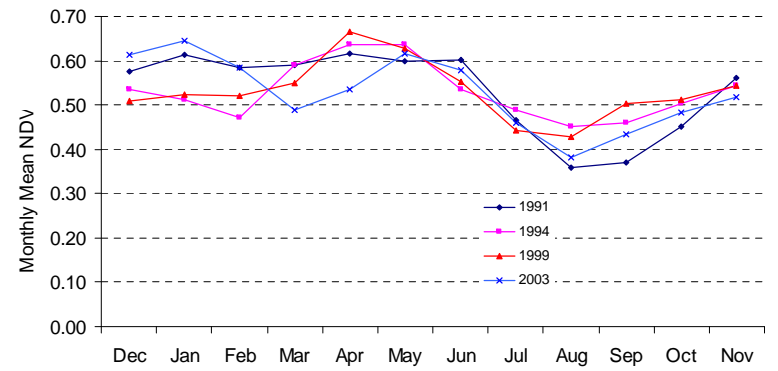

(b) Variations in Monthly Mean NDVI.

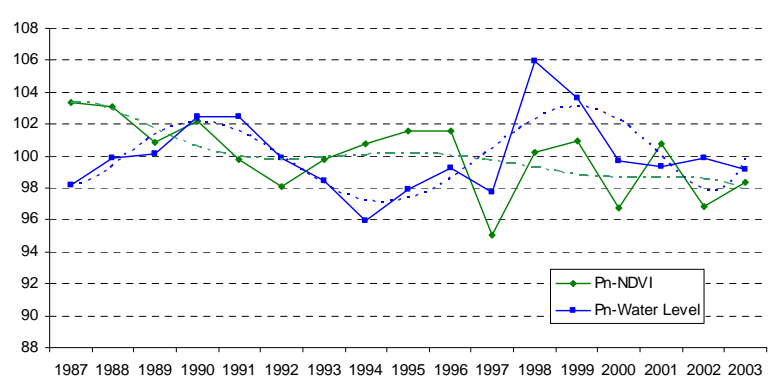

(d) WL and NDVI Departures from Normal, 1987-2003.

Figure 6: Variation of monthly means; (a) rainfall (b) NDVI (c) water levels from the tide gauge data, and (d) a plot of water levels and NDVI departures from normal (PN) for the period 1987-2003. 


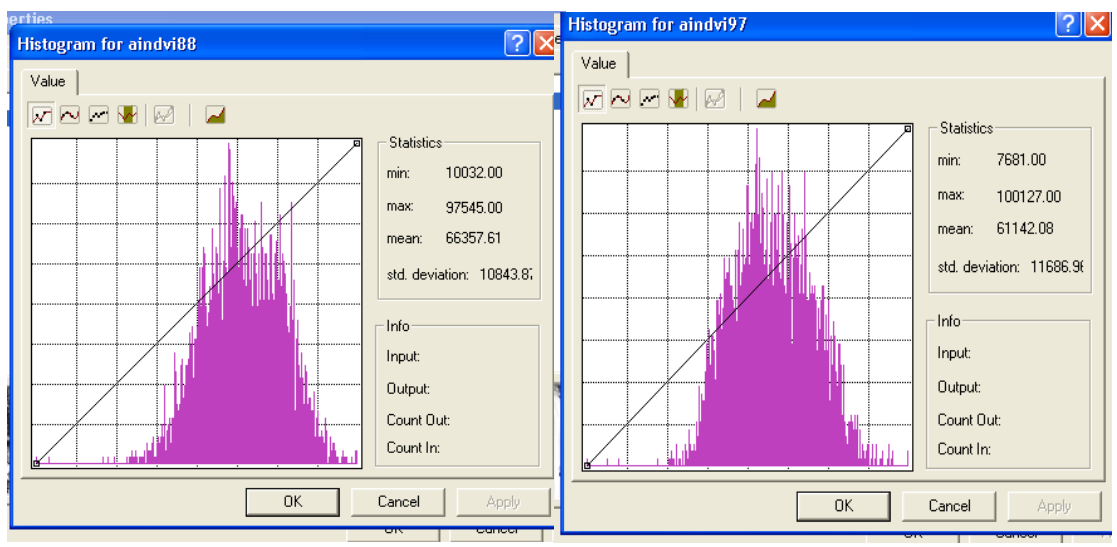

(a) Sample AINDVI distributions, 1988 and 1997.
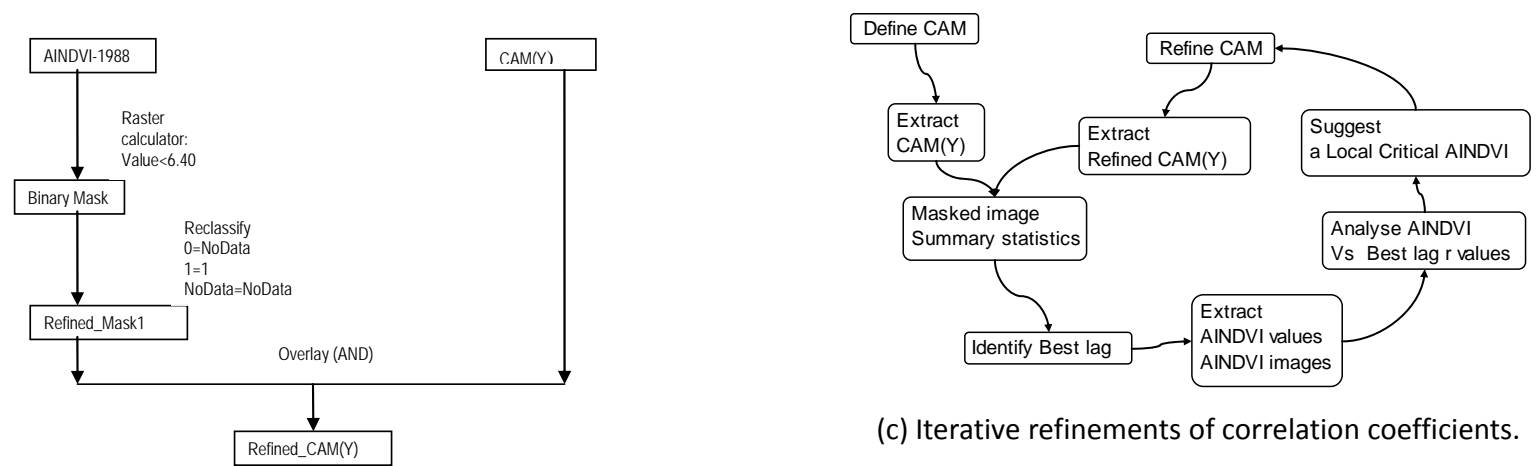

(c) Iterative refinements of correlation coefficients.

(b) Image masking using local AINDVI threshold.

Figure 7: (a) Sample AINDVI distributions, 1988 (high precipitation year) and 1997 (drought year), (b) image masking using local AINDVI threshold, and (c) iterative refinements of correlation coefficients. 


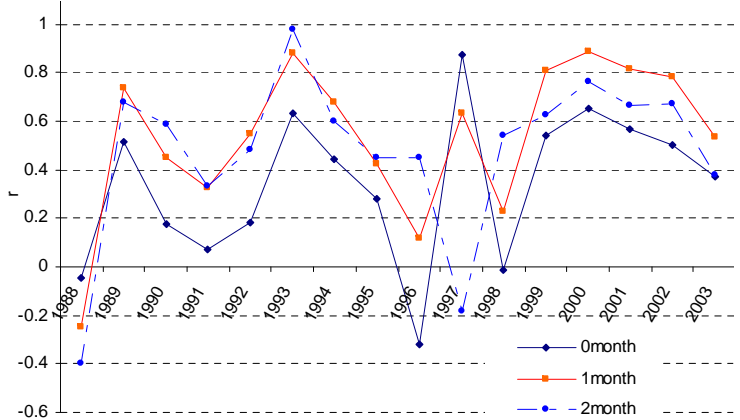

(a) NDVI lagging water levels, zero, one and two months lags.

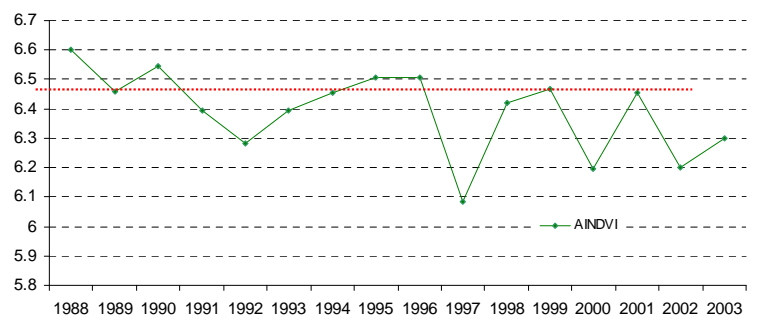

(c) Interannual Variation of AINDVI in the catchment.

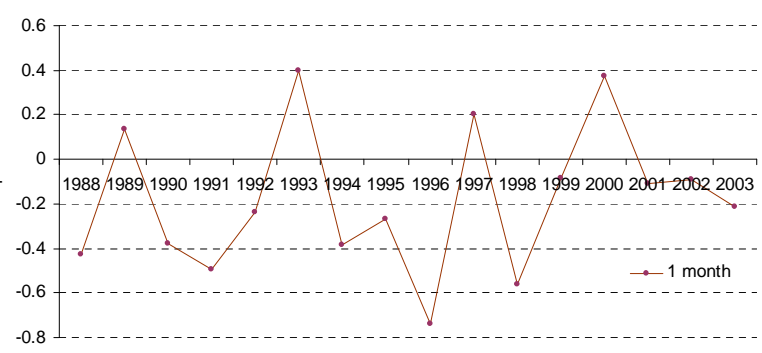

(b) Water levels lagging NDVI, one month lag

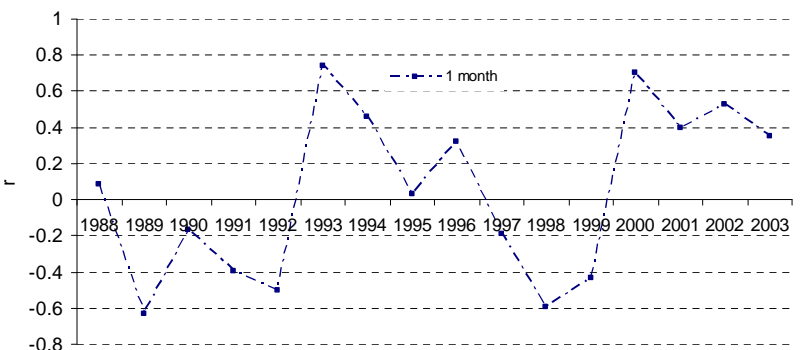

(d) SVI lagging standardised WL, one month Lag.

Figure 8: Correlation Variability; (a) NDVI lagging water levels by zero, one and twomonths, (b) water levels lagging NDVI by one-month (c) interannual variation of AINDVI in the catchment (with the exception of 1991, 1996 and 1998 (Fig. 8a), the local upper threshold AINDVI for obtaining good correlations $(r>0.5)$ is about 6.46), and (d) SVI lagging standardised WL (water levels), one-month Lag. 


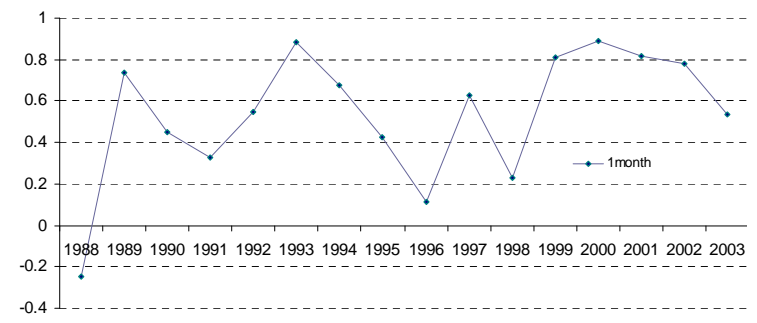

(a) $F_{g}$ lagging water levels, one month lag.

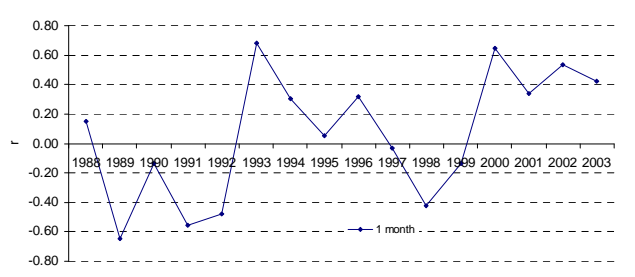

(c) NDVIA /WL Anomalies

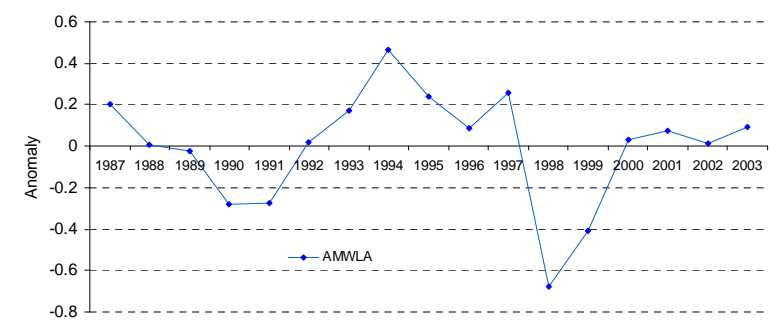

(d) Variability of AMWLA.

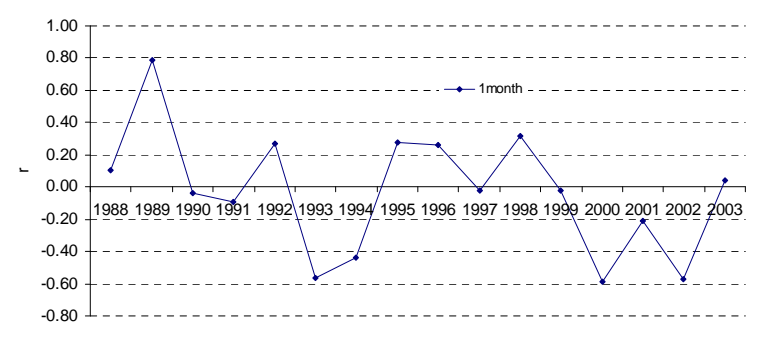

(b) NDVIA /WL.

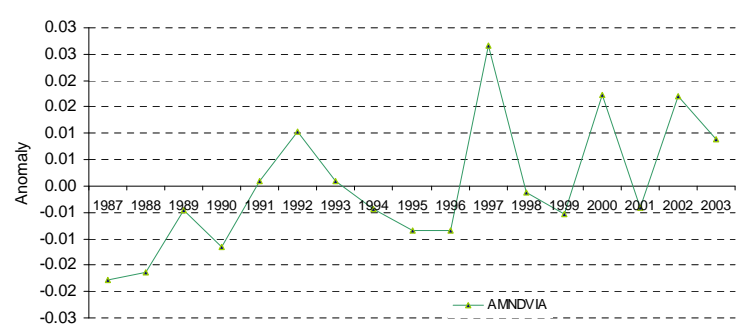

(e) Variability of annual mean NDVIA.

Figure 9: Correlation variability; (a) $F_{g}$ lagging water levels, one-month lag, (b) NDVIA /WL (water levels), (c) NDVIA /WL Anomalies, (d) variability of AMWLA, and (e) variability of annual mean NDVIA. 


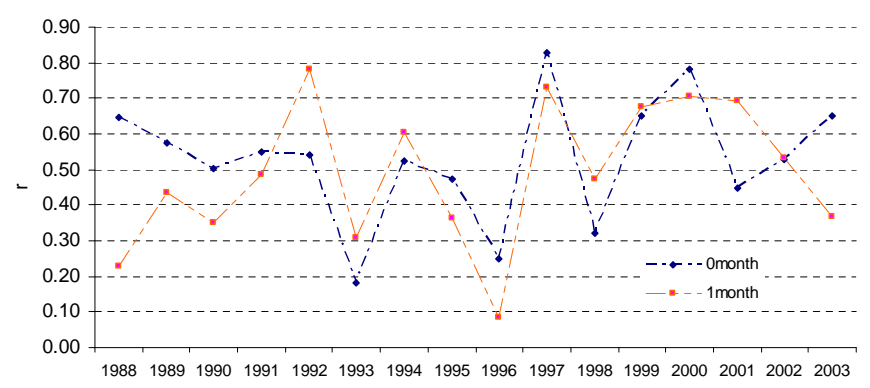

(a) NDVI differences lagging WL differences, zero and one month lag

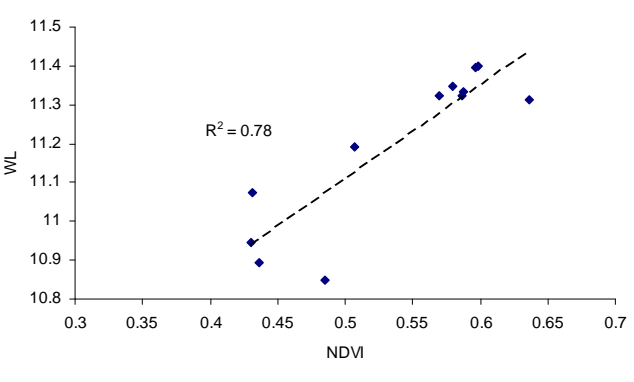

(b) NDVI lagging water levels, one month lag, 1993.

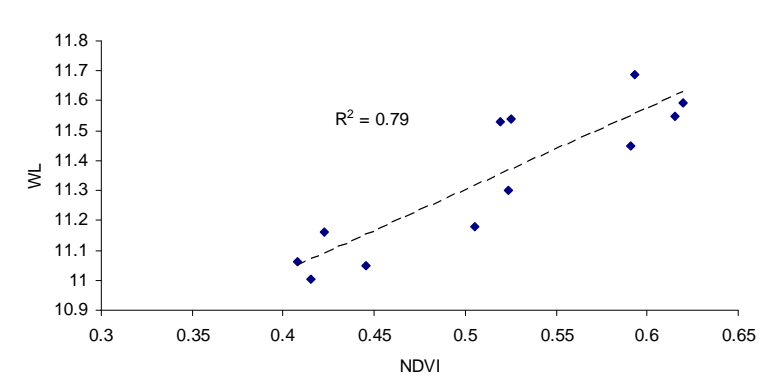

(c) NDVI lagging water levels, one month lag, 2000.

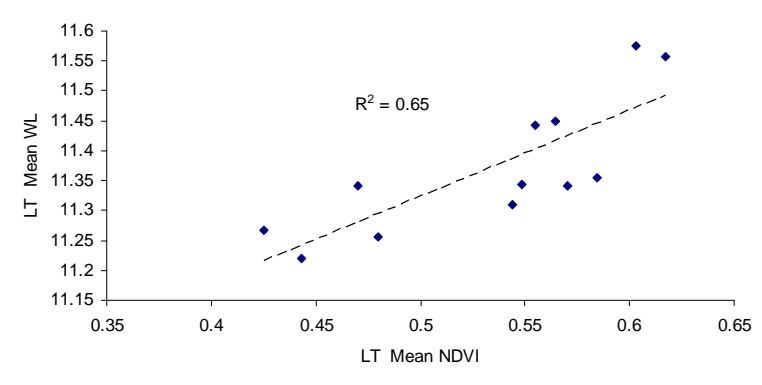

(d) Long term NDVI lagging long term water levels, one month lag.

Figure 10: Correlation Variability; (a) NDVI differences lagging WL differences at zero and one-month lag, (b) NDVI lagging water levels at one-month lag for 1993 (c) NDVI lagging water levels at one-month lag for 2000, and (d) long term NDVI lagging long-term water levels with a one-month lag. 